\title{
Terrestrial communication experiments over various regions of Indian subcontinent and tuning of Hata's model
}

\author{
M. V. S. N. Prasad • K. Ratnamala • M. Chaitanya • \\ P. K. Dalela
}

Received: 16 January 2007 /Revised: 10 May 2007 / Accepted: 10 September 2007

(C) Institut TELECOM and Springer-Verlag France 2008

\begin{abstract}
The development of various radio planning tools for the design of fixed and mobile communication systems requires radio channel measurements, comparison with various models, and the tuning of various parameters involved in the model. Based on the various land- and rail-based VHF/ UHF measurements over northern, southern, western, and eastern parts of Indian subcontinent, the parameters of Okumura-Hata model are tuned, and modified parameters for the above regions have been deduced. These can be utilized for the design and development of future broadcast systems, mobile communication systems in this region of the world.
\end{abstract}

Keywords Path loss · Measurements · Model tuning · Hata's method

\section{Introduction}

To provide better inputs for the design of future wireless communications, the communication group at National Physical Laboratory conducted various narrowband radio measurements on land-based and train-based platforms and compared number of existing radio propagation models with the measured results. The study showed that different models gave varying degrees of deviation in different regions[1-5]. It has been observed that out of all the models, the most popular model used by the cellular and other operators in their radio planning tools is the Okumura-Hata model, of course with some refinements. They generally conduct measurements in a small region of interest and attempt to fine-tune the Hata model to apply it to a larger region. This is a time-consuming procedure.

The objective of the work was to tune the parameters of this well-known model not only in a limited area but in larger parts of India to save valuable time and money on field trials for the design of new networks. Based on the experimental data collected in different contexts in VHF and UHF bands in the southern region (150 and $440 \mathrm{MHz}$ ) on land-based vehicles and in the UHF band in northern and western and eastern regions on train-based platforms $(320 \mathrm{MHz})$, an attempt is made to fine-tune the Hata model for these respective regions following the approach of Medeisis and Kajackas [6]. The results of the present study can be utilized to design macrocellular and other related mobile systems where Okumura-Hata model is being used by system operators.

\section{Experimental details}

Radio measurements have been conducted over land-based vehicles in southern India at 150 and $440 \mathrm{MHz}$ in urban,
P. K. Dalela

Mandigaon road, opp. New Manglapuri, Chatterpur,

Mehrauli, New Delhi 110030, India

e-mail: pdalela@gmail.com 
suburban, and open areas[4] and train-based measurements [1-2] in northern, western, and eastern India using various base stations. The observed results from these base stations have been utilized in the present study.

In the coastal regions of southern India(Andhra Pradesh State), field strength measurements were conducted radially from both the co-located transmitters with a radiated power of $5 \mathrm{~W}$ up to $30 \mathrm{~km}$ in different regions at 150 and $440 \mathrm{MHz}$. The whole region is a coastal zone with high humidity content. The measurements were carried out for a period of 30 days for different base station antenna heights of 16,30 , and $40 \mathrm{~m}$ with receiving antenna height of $3 \mathrm{~m}$. The base station antenna was an omni directional monopole, and the receiving antenna was a yagi of gain $12 \mathrm{dBi}$, and antenna was oriented towards base station. The field strength was monitored with a field intensity meter RFT model SMV-8 from Germany. Both the frequencies were monitored with the same equipment mounted on a open jeep. The detailed specifications of system are given in Annexure A. Sampling rate was one measurement per minute. The averaged field strength value of ten samples in $10 \mathrm{~min}$ at a given distance was converted into a path loss value. The vehicle moved at constant speeds, and the yagi antenna is oriented towards the base station. Data points amounted to 300 for each frequency and each base station antenna height. Measurements were not repeated.

In the case of train mobile measurements in both northern and western India, the same equipment and methodology was adopted. Base stations situated along the track continuously transmit the carrier at $320 \mathrm{MHz}$. They are situated at different heights with telescopic masts, and some have utilized the track side microwave towers
Fig. 1 Clutter map of north Indian base stations

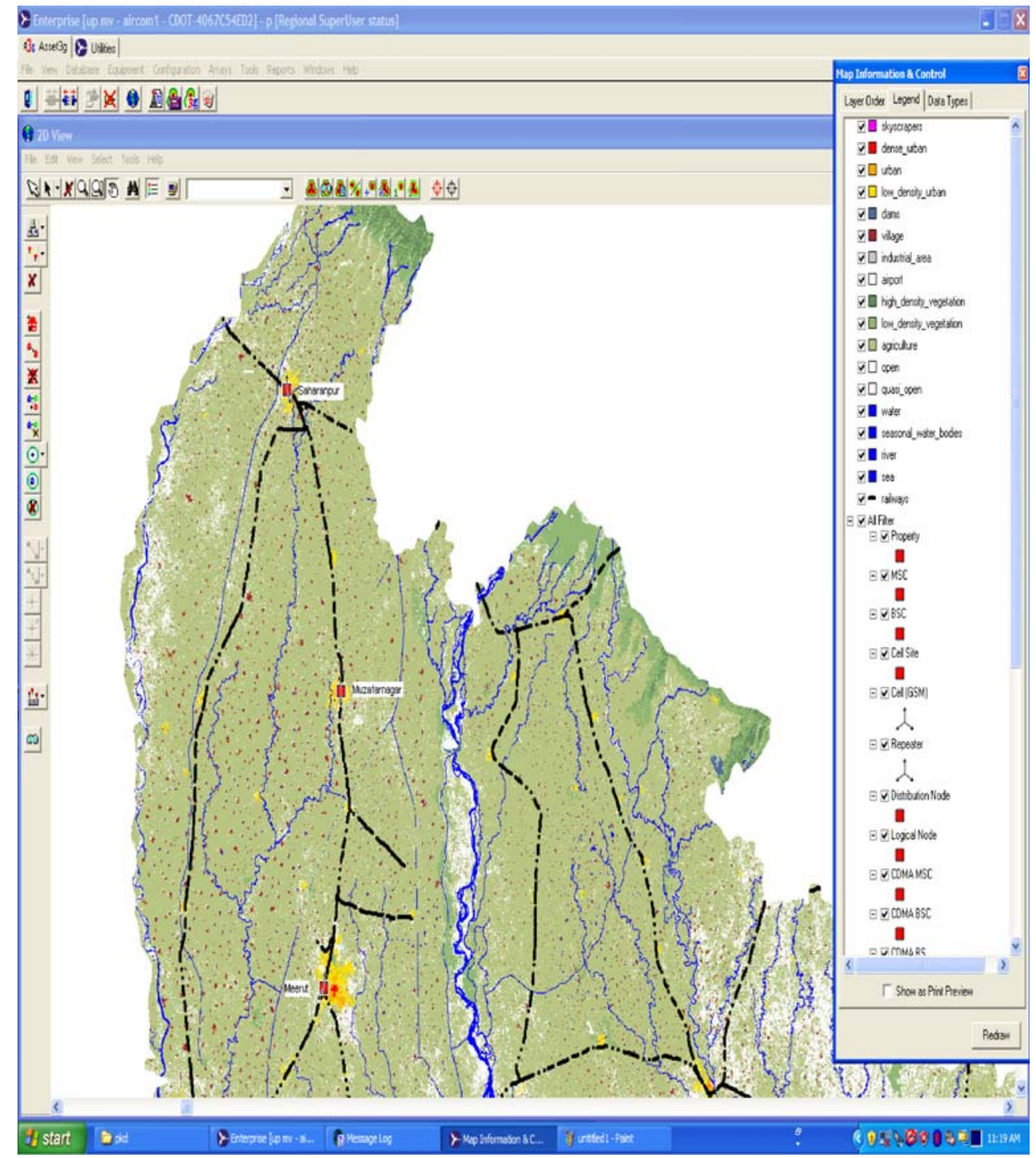




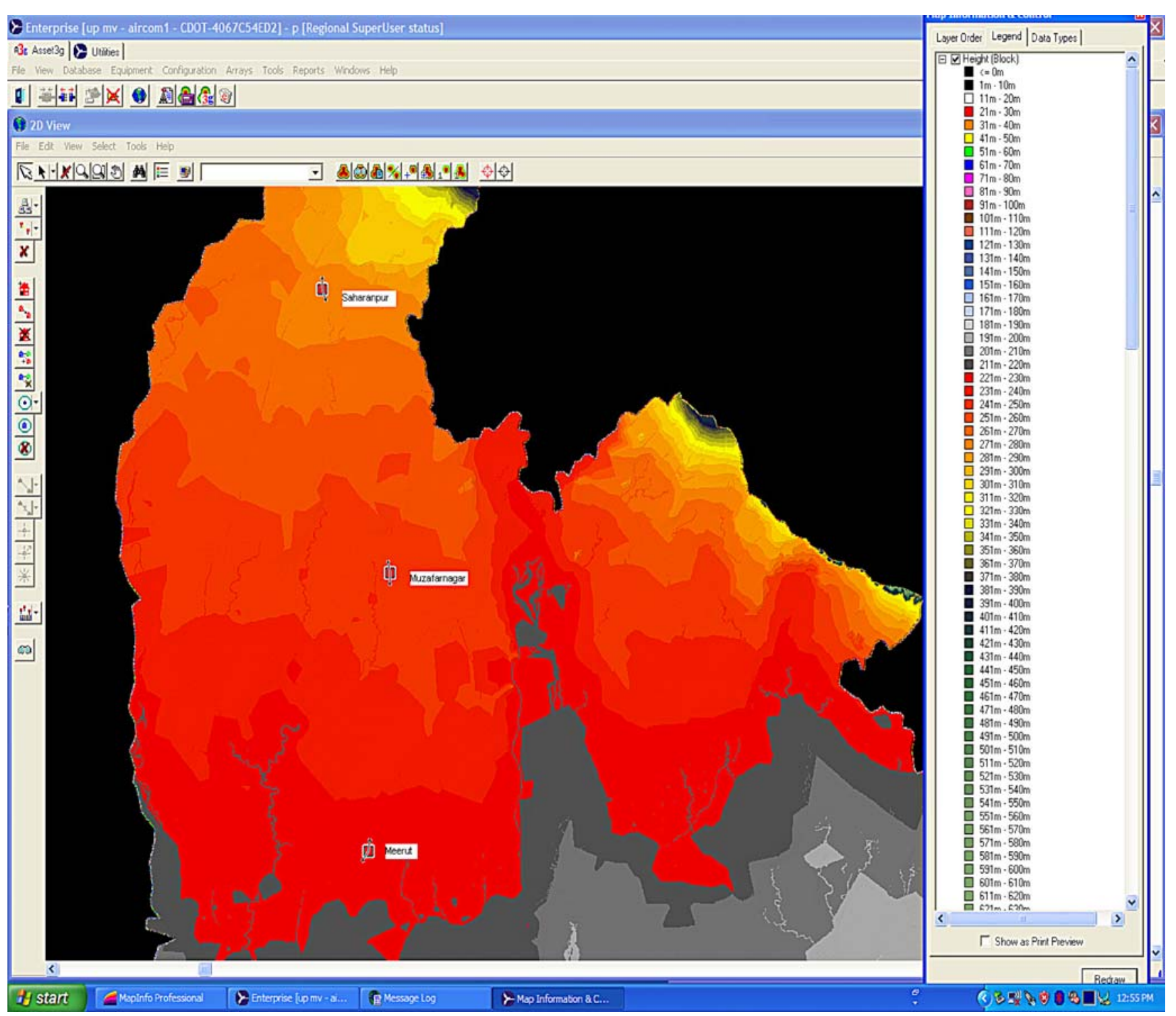

Fig. 2 Terrain variation of north Indian base stations

located at a height of $40 \mathrm{~m}$. A test coach is equipped with a calibrated receiver and computerized data logger. In addition, a chart recorder was used to record the carrier level. To relate path loss values with location, a counter of wheel rotations was necessary to drive the paper chart in a fixed linear relation to the train speed as well as having the option of storing samples at selectable intervals. A low profile omnidirectional receiving antenna was used for reception outside the train on the roof of the coach. The recorded carrier level was averaged over every $100-\mathrm{m}$ section. The receiver sensitivity shall be better than $0.5 \mu \mathrm{V}$ for $20 \mathrm{~dB} \mathrm{~S} / \mathrm{N}$ ratio measured at an radio frequency (RF) signal modulated with $1,000 \mathrm{~Hz}$ at $60 \%$ of the peak deviation into the duplexer antenna input. The dynamic adjacent channel selectivity shall be $70 \mathrm{~dB}$ or better.
Depending on the progress of the train, the base station signal is switched on. Using a signal generator, the receiver is calibrated before the start of the recording as well as after termination. The calibration curve is recorded on a PC and a chart recorder. The recording process begins when starting from or passing through a station. This point with exact kilometerage is important for synchronizing test equipment. When the signal level falls well below a useful level, the recording is terminated at the next station again with exact kilometerage. The mobile equipment in the coach worked with a petrol generator. One of the objectives of this measurement program is to determine the coverage area of the base station located along the railway track for designing future train mobile communication systems. According to the coverage objectives for mobile radio 


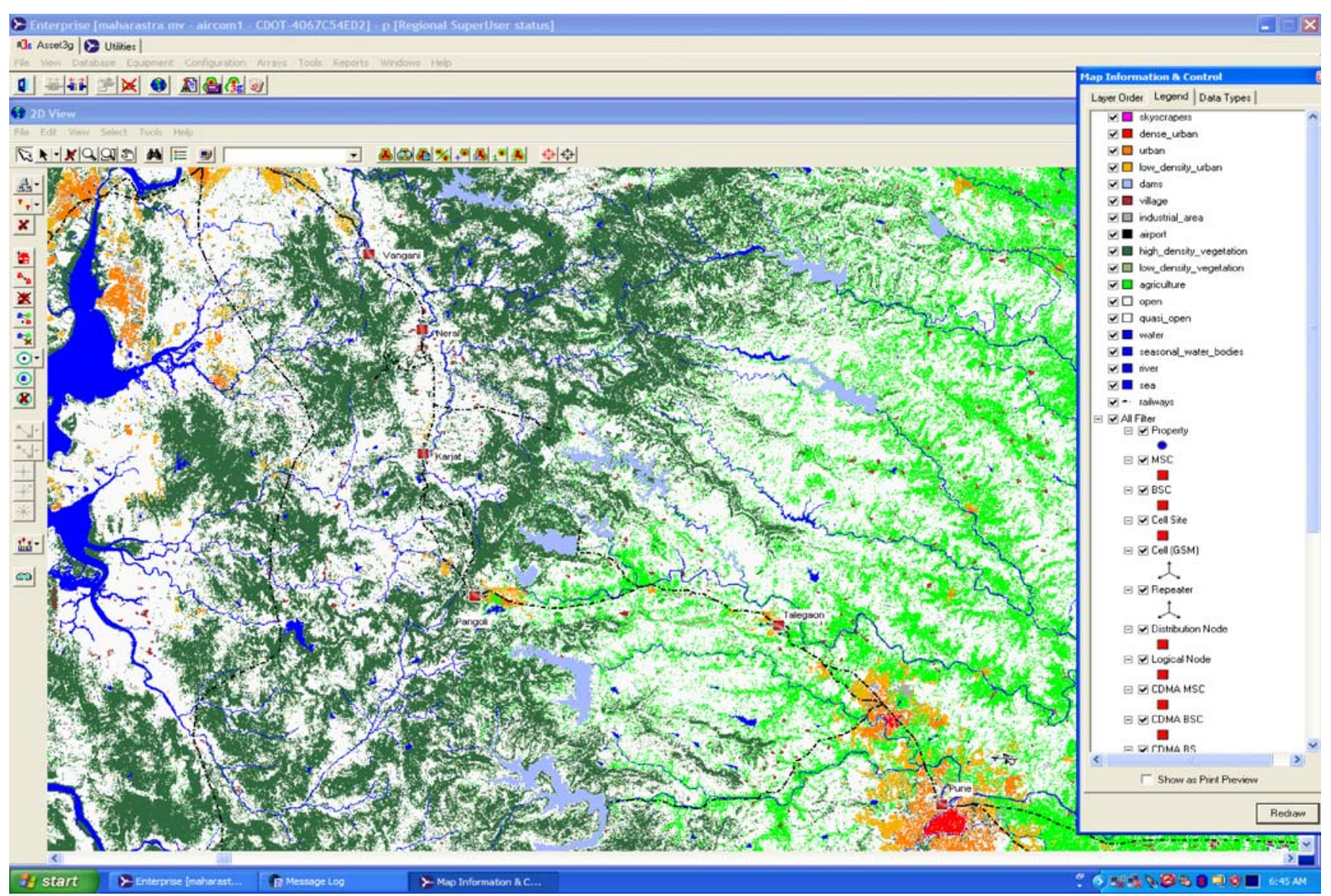

Fig. 3 Clutter map of west Indian base stations

systems utilized by railways as per the regulations of International Union of railways, satisfactory coverage of an entire line is achieved if a minimum reception signal can be attained more than $95 \%$ of the track distance and for $95 \%$ of the time. In the northern Indian plains, the total distance between base station Meerut and last base station Saharanpur was $160 \mathrm{~km}$. Throughout this distance, measurements were conducted in the train in one go only. Similarly, in the western region, the total distance between base station Vangani and the last base station Pune was $136 \mathrm{~km}$ encompassing various types of environments ranging from urban to open.. In the case of Eastern India, the total length of the path was $100 \mathrm{~km}$ spanning nine base stations. The corresponding data points over northern India are 1600, western India 1360, eastern India 1000. In the case of train measurements, low profile omnidirectional antenna was used outside the train on top of the coach to avoid the shielding effects. Slightly directing antenna radiation patterns have been used for reduction of radiation in unwanted direction and obtaining moderate antenna gain of $5 \mathrm{~dB}$. When the track has minimum number of turns, slightly directing antenna are used and when it is zigzag, omnidirectional antenna are used, and when it is straight, highly directing antenna can be used. Antenna are vertically polarized, with $50 \Omega$ impedance.

Table 4 in Annexure B shows the details of base stations, their heights above the ground, transmitter power, etc.

\section{Environmental description}

\subsection{Southern India environment}

These measurements were conducted in the Andhra Pradesh region of southern India. The region consists of three storey buildings with street widths of order of $10 \mathrm{~m}$. It is a medium urban region. Suburban region is characterized by low-density single storey dwelling units with some trees. Quasi-open area consists of terrain partly with agricultural lands, partly woods and trees. As it is a coastal area, a lot of greenery is present throughout the year and at some points, the region is crossed by water bodies. Open region consists of flat open areas with extensive agricultural rice fields and is sparsely populated. In the present study, measurements conducted in open regions are only included. The height 
above the mean sea level varies from 1 to $10 \mathrm{~m}$, as it is close to the coast and contains water bodies also.

\subsection{Northern India environment}

The base stations utilized in the present study are Meerut, Muzzafarnagar, and Saharanpur base stations. Between Meerut and Saharanpur, the terrain is flat, having rolling plains and comes under the category of open region with agriculture fields and intermittent trees. The region can be taken as suburban category for the distances extending up to $1 \mathrm{~km}$ from the base stations.

\subsection{Western India environment}

The region around base stations starting from Vangani up to Pune is suburban, and the region between these base stations is open with green fields and agricultural lands. The last base station Pune is a small city with medium urban environment prevailing up to $2 \mathrm{~km}$ from the base station, and it is suburban region thereafter up to $4 \mathrm{~km}$.
Beyond this, it comes under open category. Part of the terrain in the present study is elevated with many ghat sections. The terrain is flat and passing through a broad valley interspersed with hills in between. The remaining part close to Pune base station is plateau area. Microwave towers located by the track side were utilized as base stations. The terrain irregularity in the plateau area is $50 \mathrm{~m}$, which is an average value. The terrain encountered in the north Indian train radio measurements reported in [3] is different from the western Indian environment. There the terrain was open, flat with urban, suburban, and open demarcations. Hence, mobile radio propagation characteristics would be totally different in these regions.

\subsection{Eastern India environment}

The railway track from Chakradharpur to Rourkela runs through deep cuttings and a tunnel in between. Chakradharpur depicts medium urban near the base station, and as one moves away from the station, suburban and open type environment prevails. At Chakradharpur end, the terrain is situated at $220 \mathrm{~m}$

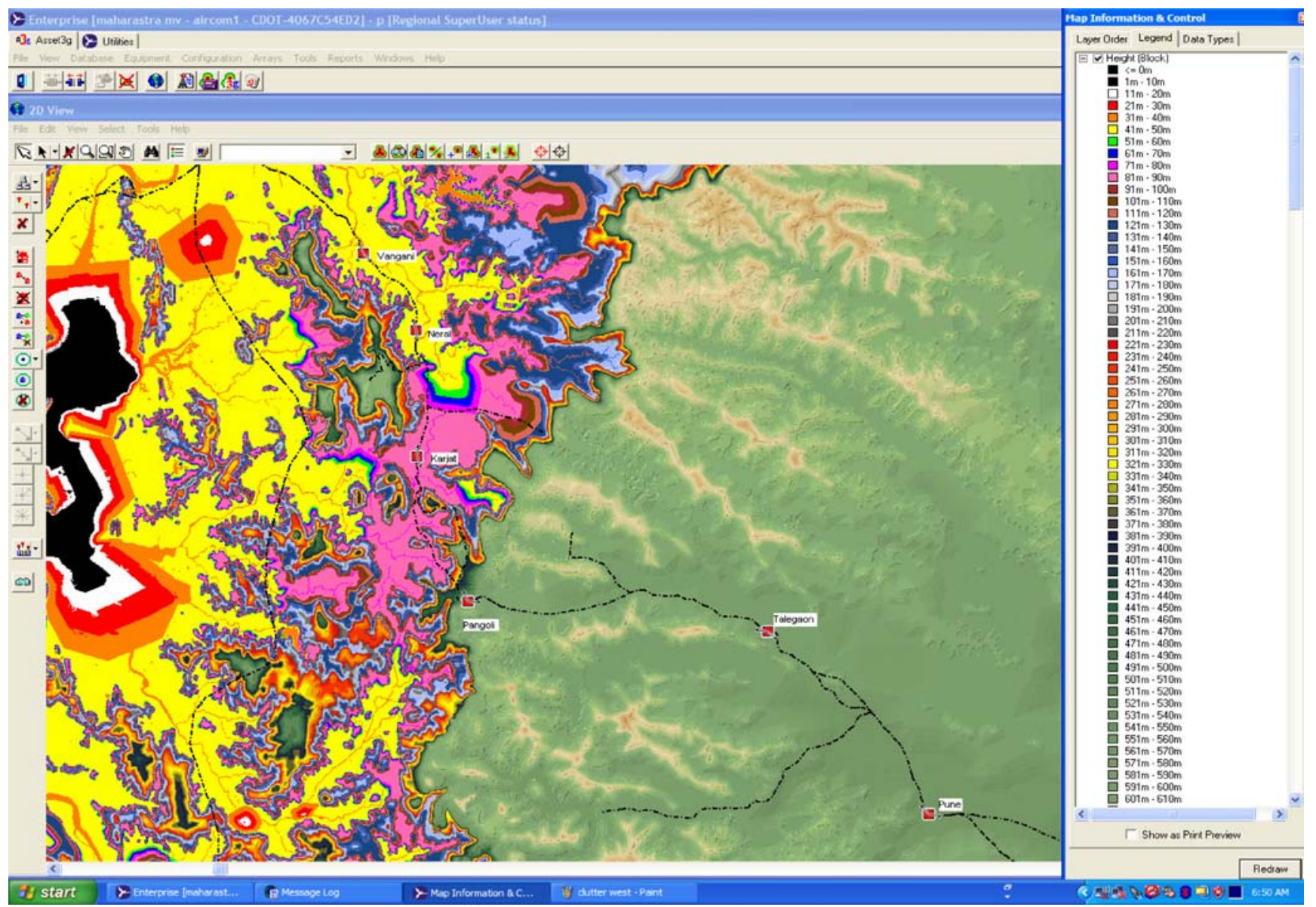

Fig. 4 Terrain variation of west Indian base stations 


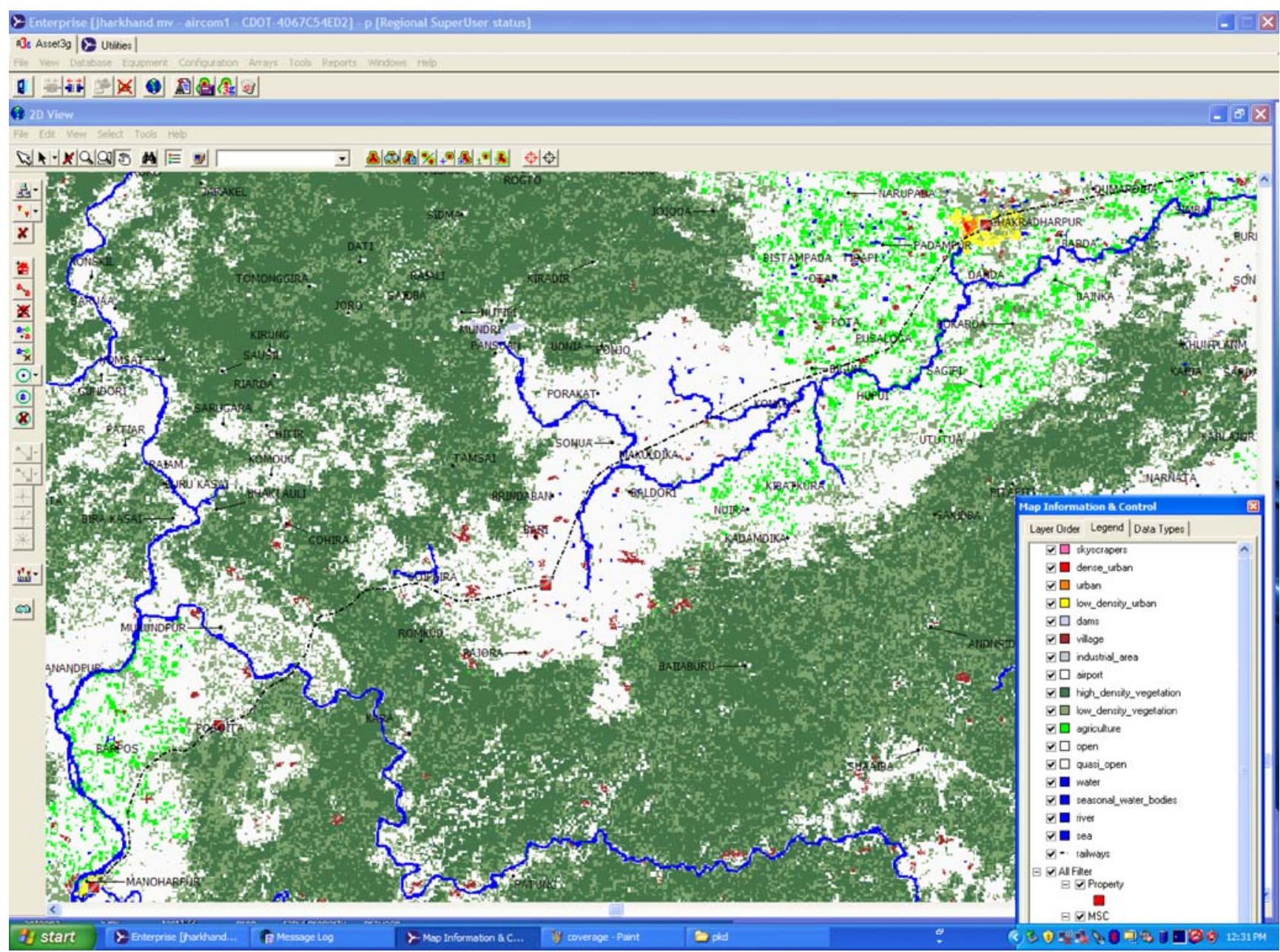

Fig. 5 Clutter map of east Indian base stations

above mean sea level (msl), and this increases to $330 \mathrm{~m}$ above $\mathrm{msl}$ as one moves towards Goilkera. In between, at $6 \mathrm{~km}$ distance from Goilkera base station, the terrain levels is $290 \mathrm{~m}$. The terrain is sloping upwards as one moves from Chakradharpur to Goilkera. Near Goilkera station, suburban environment prevails. From Goilkera to Mahadevsal, open environment with few trees and bushes is seen. At Posoita, which is the next base station, the terrain level comes down to $280 \mathrm{~m}$, and at $3 \mathrm{~km}$ distance from Posoita base station, the terrain level comes to $242 \mathrm{~m}$, and a hill is seen at a distance of $6 \mathrm{~km}$ touching a height of $363 \mathrm{~m}$. At $6.38 \mathrm{~km}$ distance from Posoita base station, the terrain height comes to $300 \mathrm{~m}$ and remains at $320 \mathrm{~m}$ height for the remaining part of the distance. Along the track, some agricultural fields are seen. Between Posoita and Manoharpur, the environment is considered to be open except for the suburban nature near the base stations. At Manoharpur base station, the terrain level is $219 \mathrm{~m}$, and the terrain remains flat up to a distance of $4 \mathrm{~km}$ from Manoharpur base station. Terrain reaches $240 \mathrm{~m}$ at $5 \mathrm{~km}$ distance and remains at that level till Posoita base station end. Between Manoharpur and Jaraikela, the environment is also open with small roadside bushes and agricultural fields in between. At Jaraikela, the terrain level is $224 \mathrm{~m}$ above mean sea level, and at $2 \mathrm{~km}$ distance, the terrain reaches $240 \mathrm{~m}$, and from $3 \mathrm{~km}$ distance, it drops down to $220 \mathrm{~m}$. Between Jaraikela and Bondamunda, the same kind of open environment exists. At Bondamunda base station, the terrain levels above msl is $200 \mathrm{~m}$, and beyond $5.5 \mathrm{~km}$, the terrain starts sloping up and reaches $240 \mathrm{~m}$, and at $7 \mathrm{~km}$, it remains the same up to $9.53 \mathrm{~km}$, i.e., up to Jaraikela. Between Bondamunda and Rourkela, the environment near the Rourkela base station is medium urban up to $2 \mathrm{~km}$ from Rourkela base station, and the remaining environment is open type. Rourkela is an industrialized town.

Railway environment is different from the traditional road environment. A $25-\mathrm{kV}$ line runs along the track generating harmonics of radio waves causing electromagnetic interference. 
The height of coach is at a higher elevation compared with the traditional road-based vehicle height. This may improve signal levels due to height gain characteristics of antenna. The propagation environment consists of plane earth, sidewalls, terrain cuttings, over bridges, masts, wires, tunnels, crossing trains, etc. [7]. Propagation paths in this environment is complicated due to different propagation mechanisms like reflection, diffraction, scattering, etc. Railway environments are first divided into between stations or station yards. In station yard, as there are some railway structures, multiple interference occurs. In between the stations, environment is divided into traditional classification like urban, suburban, or open. This has been described in the above paragraphs.

To get a feel of the environment, clutter maps and terrain variation of north Indian, west Indian, east Indian, and south Indian regions are shown in Figs. 1, 2, 3, 4, 5, 6, 7, and 8 . These have been generated based on digital terrain data with a resolution of $50 \mathrm{~m}$ using asset tool of aircom. The figures are depicted in the end.

\section{Methodology}

(a) Initially, the mean error and standard deviation of prediction errors obtained for all the paths from Hata's method are given in Table 5 shown in Annexure B.

In the case of 440 and $\& 150 \mathrm{MHz}$ measurements, 40, 30, and $16 \mathrm{~m}$ refer to the positions of base station antenna heights. In all the cases, prediction was calculated as the difference between observed loss and predicted loss. The negative sign before the mean error shows that prediction method is overestimating the path loss. Standard deviations observed over northern India are in the range of 3-5 dB,

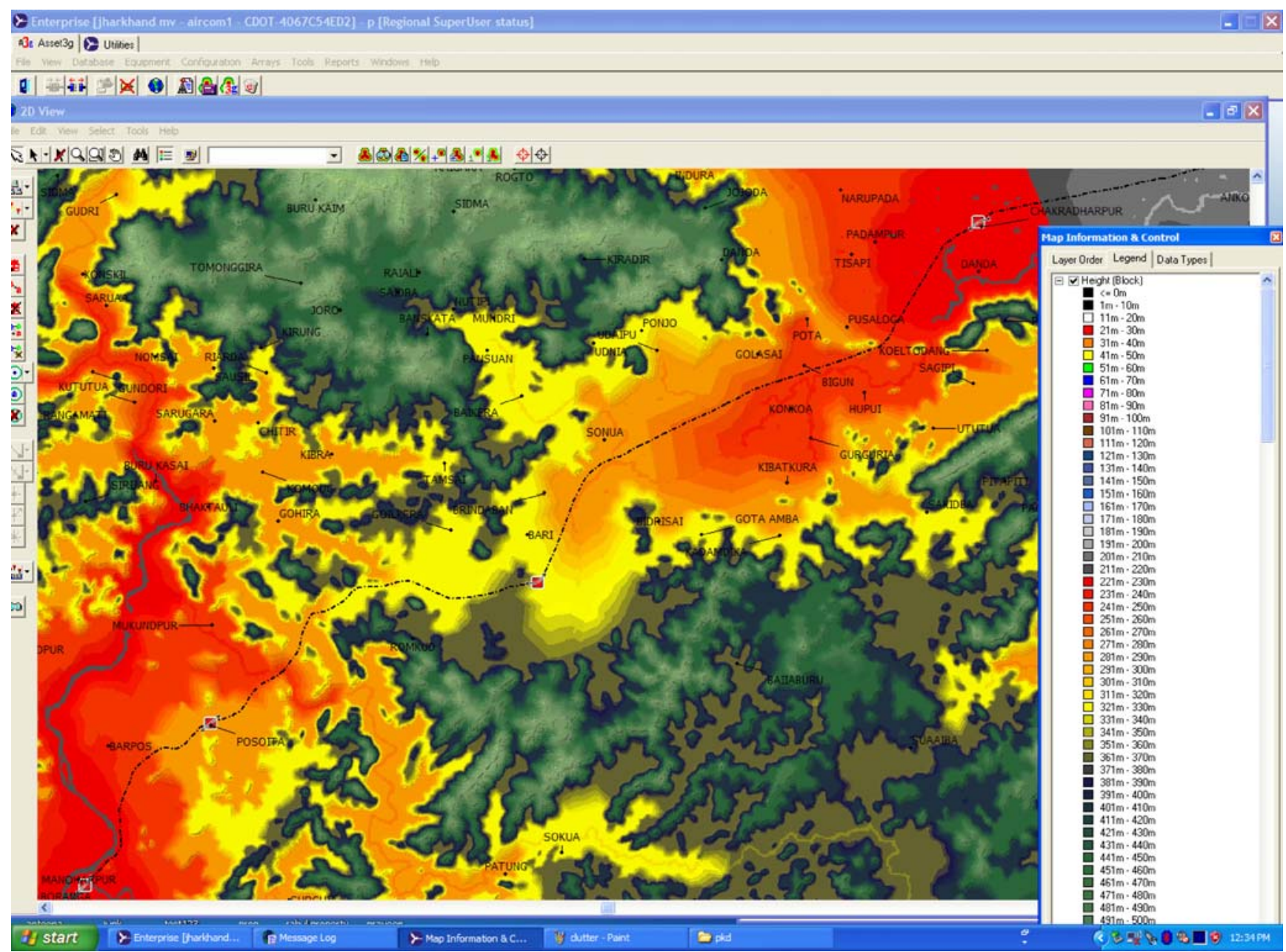

Fig. 6 Terrain variation of east Indian base stations 


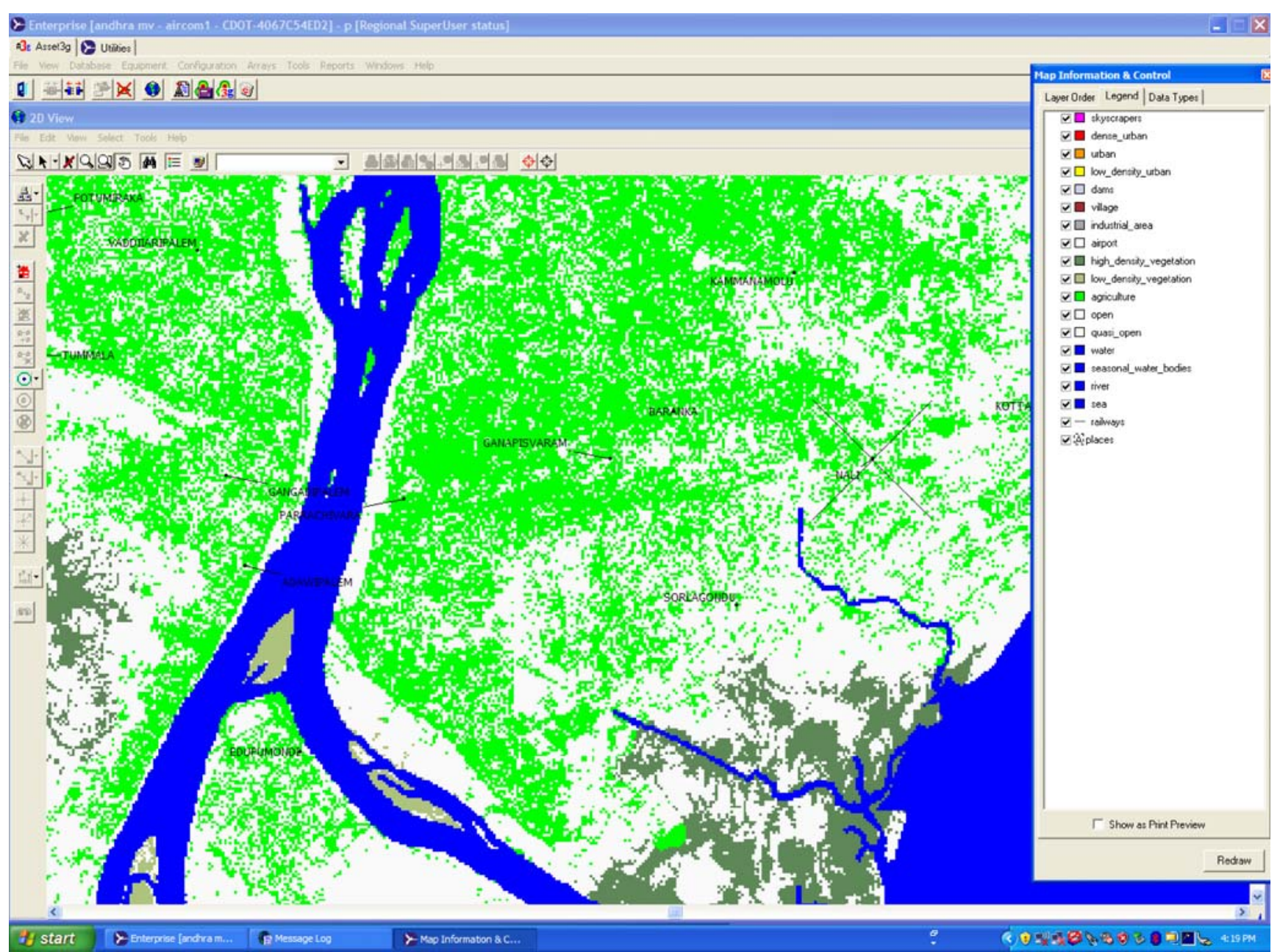

Fig. 7 Clutter map of south Indian base stations

and Hata method performed well here. Over western and eastern India, standard deviations ranged from 5 to $12 \mathrm{~dB}$. Over southern India, the method exhibited minimum standard deviation. In view of the wide variability of the standard deviations, an attempt to tune the Hata's method was attempted.

(b) Tuning methodology:

Okumara's prediction of median path loss [8] are usually calculated using Hata's approximations as follows [9].

$L=A+B \log R-\left(h_{\mathrm{m}}\right)$

where

A $\quad 69.55+26.16 \log f-13.82 \log h_{\mathrm{b}}$,

$B \quad 44.9-6.55 \log h_{\mathrm{b}}$,

$a\left(h_{\mathrm{m})} \quad\left(1.1^{*} \log (f)-0.7\right) h_{\mathrm{m}}-\left(1.56^{*} \log (f)-0.8\right)\right.$

$f \quad$ operating frequency $\mathrm{MHz}$

$h_{\mathrm{b}} \quad$ effective height of transmitting antenna in meters

$h_{\mathrm{m}} \quad$ effective height of receiving antenna in meters

$R \quad$ distance from transmitter $(\mathrm{km})$
The relation between field strength in $\mathrm{dB} \mu \mathrm{V} / \mathrm{m}$, path loss is given in terms of transmitted power, antenna gain, frequency as $L(\mathrm{~dB})=137+20 \log f+P_{\mathrm{t}}+G_{\mathrm{t}}-E$

As $P_{\mathrm{t}}$ and $G_{\mathrm{t}}$ are known, $E$ can be calculated from Eq. 2 by substituting for $L$ from Eq. 1 . Then, we get

$$
\begin{aligned}
E_{\mathrm{R}}= & 35.45+P_{\mathrm{t}}-6.16 \log (f)+13.82 \log \left(h_{\mathrm{b}}\right) \\
& +a\left(h_{\mathrm{m}}\right)-\left(44.9-6.55 \log \left(h_{\mathrm{b}}\right)\right) \log R^{\gamma}
\end{aligned}
$$

This is the equation obtained by Medesis and Kajackas [6].

$E_{\mathrm{R}}$ received field strength in $\mathrm{dB}(\mu \mathrm{V} / \mathrm{m})$

$P_{\mathrm{t}} \quad$ radiated power, $\mathrm{dBW}$

$f \quad$ operating frequency $(\mathrm{MHz})$

$h_{\mathrm{b}} \quad$ Effective height of transmitting antenna in meters

$h_{\mathrm{m}}$ effective height of receiving antenna in meters

$$
\begin{aligned}
a\left(h_{\mathrm{m}}\right)= & (1.1 * \log (f)-0.7) h_{\mathrm{m}} \\
& -\left(1.56^{*} \log (f)-0.8\right)
\end{aligned}
$$


$R$ distance from transmitter $(\mathrm{km})$

$\gamma \quad 1$ for $R \leq 20 \mathrm{~km}$

$$
\begin{gathered}
\gamma=1+\left(0.14+1.87 * 10^{-1} * f+1.07 * 10^{-3} * h_{\mathrm{b}}\right) \\
*(\log (R / 20))^{0.8} \text { for } 20 \leq \mathrm{R} \leq 100 \mathrm{~km}
\end{gathered}
$$

The three important parameters are initial offset parameter $\left(E_{0}\right)$, initial system design parameter $\left(E_{\mathrm{s}}\right)$, and parameter establishing slope of the model curve $(\gamma)$.

$E_{0}=35.55 \mathrm{~dB}(\mu \mathrm{V} / \mathrm{m})$

$E_{\text {sys }}=P_{\mathrm{t}}-6.16^{*} \log (f)+13.82 * \log \left(h_{\mathrm{b}}\right)+a\left(h_{\mathrm{m}}\right)$

$\gamma$ sys $=-\gamma\left(44.9-6.55^{*} \log \left(h_{\mathrm{b}}\right)\right)$

Authors [6] have suggested that for the tuning of the model, only two parameters may be most relevant and sufficient, initial offset and slope of the curve $\gamma$. System design parameters should not be subjected to tuning. Authors approach is based on statistical method of least squares (details can be seen in the authors' paper). Based on this approach, $E_{0}$ and $\gamma$ for different frequencies, environments have been deduced.

\section{Results}

Based on the above approach, $E_{0}$ and $\gamma$ have been deduced for all the above base stations and are shown below for urban, rural, suburban zones (Table 1). In the case of landbased measurements at $150 \mathrm{MHz}$, the values of $E_{0}$ vary from 77.56 to 77.68 and $\gamma$ from 0.99 to 1.002 for base station antenna heights of 16,30 , and $40 \mathrm{~m}$. In the case of Lithuania, authors have obtained around 40 for rural area at $160 \mathrm{MHz}$. At $440 \mathrm{MHz}$, the corresponding values of $E_{0}$ range from 65.2 to 66.19 , and $\gamma$ varies from 0.99 to 1.01 .

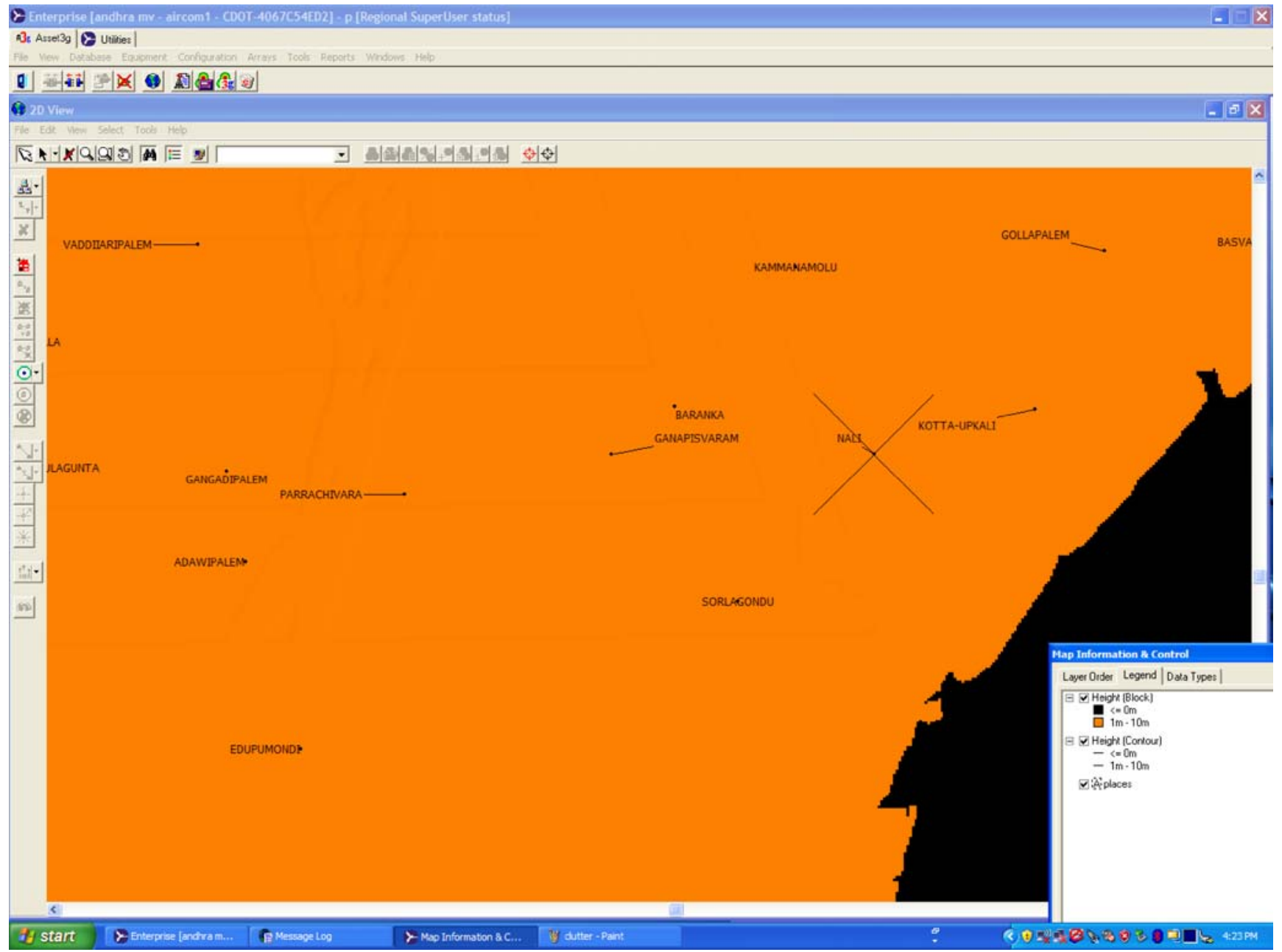

Fig. 8 Terrain variation of south Indian base stations 
Table 1 Tuned values for different regions

\begin{tabular}{|c|c|c|c|c|c|c|c|c|c|}
\hline \multirow[t]{2}{*}{ Transmitting antenna height } & \multirow[t]{2}{*}{$320 \mathrm{MHz}$} & \multicolumn{4}{|l|}{$E_{0}$} & \multicolumn{4}{|l|}{$\gamma$} \\
\hline & & $440 \mathrm{MHz}$ & $150 \mathrm{MHz}$ & Left & Right & $440 \mathrm{MHz}$ & $150 \mathrm{MHz}$ & Left & Right \\
\hline \multicolumn{10}{|l|}{ Southern region } \\
\hline $40 \mathrm{~m}$ & & 66.19 & 77.65 & & & 1.01 & 1.00 & & \\
\hline $30 \mathrm{~m}$ & & 65.23 & 77.78 & & & 0.99 & 1.002 & & \\
\hline $16 \mathrm{~m}$ & & 65.97 & 77.56 & & & 1.00 & 0.99 & & \\
\hline \multicolumn{10}{|l|}{ Northern and western regions } \\
\hline $40 \mathrm{~m}$ & Meerut & & & 50.85 & 42.22 & & & 1.17 & 0.95 \\
\hline $40 \mathrm{~m}$ & Muzaffarnagar & & & 55.4 & 52.71 & & & 1.15 & 1.29 \\
\hline $40 \mathrm{~m}$ & Saharanpur & & & 39.26 & - & & & 0.88 & - \\
\hline $26 \mathrm{~m}$ & Vangani & & & 52.81 & 25.24 & & & 1.31 & 1.08 \\
\hline $25 \mathrm{~m}$ & Neral & & & 45.09 & - & & & 1.43 & \\
\hline $46 \mathrm{~m}$ & Pangoli & & & 55.25 & - & & & 0.948 & - \\
\hline $115 \mathrm{~m}$ & Talegaon & & & 59.65 & & & & 1.8 & \\
\hline $60 \mathrm{~m}$ & Pune & & & 32.38 & - & & & 0.83 & - \\
\hline \multicolumn{10}{|l|}{ Eastern region } \\
\hline $37 \mathrm{~m}$ & Chakradarpur & & & - & 50.47 & & & - & 1.01 \\
\hline $37 \mathrm{~m}$ & Goilkera & & & 52.35 & 42.25 & & & 1.77 & 0.939 \\
\hline $50 \mathrm{~m}$ & Mahadevsal (T.T) & & & 37 & 26.36 & & & 1.11 & 0.79 \\
\hline $22 \mathrm{~m}$ & Mahadevsal & & & 15.13 & 44.39 & & & 0.97 & 1.22 \\
\hline $29 \mathrm{~m}$ & Posoita & & & 32.38 & 28.04 & & & 0.97 & 0.89 \\
\hline $31 \mathrm{~m}$ & Manoharpur & & & 45.35 & 53.46 & & & 0.94 & 1.35 \\
\hline $35 \mathrm{~m}$ & Bondamunda & & & - & 52.04 & & & - & 1.00 \\
\hline $200 \mathrm{~m}$ & Rourkela (P\&T) & & & - & 55.4 & & & - & 1.2 \\
\hline $18 \mathrm{~m}$ & Jaraikela & & & 43.74 & 41.34 & & & 1.16 & 0.92 \\
\hline
\end{tabular}

They are almost constant. Russian authors reported 50 and 1.2 at $450 \mathrm{MHz}$. In the case of northern India rural zones at $320 \mathrm{MHz}$, values of $\mathrm{E}_{0}$ varied from 39 to 55 , and $\gamma$ varied from 0.88 to 1.17 . In the case of Western India, values of $E_{0}$ varied from 32 to 55 and $\gamma$ from 0.83 to 1.43 . In the eastern India, most of the base stations exhibited 40-50, and base stations like Goilkera, Mahadevsal, and Posoita exhibited still lower values. Here, the terrain is steeply changing with some kind of ghat sections and elevated type in between. These lead to high path losses and relatively lower values of $E_{0}$ compared with northern, western, and southern paths. Southern paths where measurements were conducted exhibited typical open environment with very smooth changes in terrain. Lowest values are seen in southern India, and highest values are observed in eastern part of India. This shows the widely changing environment of the subcontinent. The parameter
$E_{0}$ depends on the environment, the frequency, and antenna heights. In a random environment, Blaunstein [10] advocates the general type of Hata equation which is valid for a macro-cell environment.

$$
\begin{aligned}
L= & a_{0}+a_{f} \log f_{\mathrm{MHZ}}+a_{\mathrm{d}} \log d_{\mathrm{km}} \\
& -10 \log G_{1}-10 \log G_{2}+L_{\mathrm{SF}}+L_{\mathrm{FF}}
\end{aligned}
$$

where the parameter $a_{0}$ includes the offset and depends on the environment, the frequency, and antenna heights, and a typical value is around $45 \mathrm{~dB}$. This is analogous to $E_{0}$ in the above methodology. The parameter $a_{\mathrm{f}}$ depends on the environment and additional diffraction losses and as such, typically has free space values between 25 and 30 instead of 20 . The parameter $a_{\mathrm{d}}$ depends on the environments and has values between 30 and 40. This could be analogous to $\gamma$ and not equal to it in magnitude. Antenna gains are frequencydependent balancing out some of the propagation loss. For
Table 2 Route 1 measured in the open region of Indjija

\begin{tabular}{llllll}
\hline & $A_{0}^{1}$ & $A_{1}^{1}$ & SD & RMS error & Mean error \\
\hline LS & 45.95 & 100.6 & 6.04 & 36.5 & 20.2 \\
IRLS & 47.91 & 101.0 & 6.04 & 38.0 & 18.4 \\
\hline
\end{tabular}

Table 3 Route II measured in the sub-urban region of Indjija

\begin{tabular}{llllll}
\hline & $A_{0}^{1}$ & $A_{1}^{1}$ & SD & RMS error & Mean error \\
\hline LS & 43.20 & 68.93 & 4.96 & 24.52 & 17.36 \\
IRLS & 44.17 & 80.55 & 4.96 & 27.1 & 14.56 \\
\hline
\end{tabular}


large angular spreads, the antenna gains will tend to $0 \mathrm{~dB}$ independent of their original values.

Simi et al. [11] have proposed modified least square (LS) algorithm that decreases maximum error of predicted signal without influence on standard deviation compared to LS method in Ericsson's TEMS cellphone radio planning tool. Authors have performed RF field measurements carried out at many locations in Serbia. In the case of route 1 (Table 2) measured in the region of Indjija, coefficients $A_{0}^{1}$ and $A_{1}^{1}$ for LS are 45.95 and 100.6, and for iterative re-weighted LS algorithm (IRLS), the values are 47.31 and 101.0. Here, maximal error is decreased while r.m.s. error is increased.

The Ericsson's modification of Okumura-Hata model is known as 9999 algorithm. It is without knife-edge and spherical earth loss contribution given by

$$
\begin{aligned}
L= & A_{0}^{1}+A_{1}^{1} \log d+A_{2} \log H_{\text {eff }}+A_{3} \log d \cdot \log H_{\text {eff }} \\
& -3.2\left[\log \left(11.75 H_{\mathrm{m}}\right)\right]^{2}+g(f)
\end{aligned}
$$

where $A_{0}^{1}=A_{0}+\mu_{\mathrm{mob}}$, and $\mu_{\mathrm{mob}}$ is value in $\mathrm{dB}$ of land usage (clutter) type where mobile is located, $d$ is the distance from base station antenna to mobile in kilometer. $H_{\text {eff }}$ is the effective height of base station antenna, $H_{\mathrm{m}}$ is height of mobile antenna in meters, and $g(f)=44.49 \log f-4.78$ $(\log f)^{2}$ where $f$ is frequency in MHz. A perusal of the above with the methodology shows that $A_{0}^{1}$ is analogous to parameter $E_{0}$ in our study, and $A_{1}^{1}$ is analogous to $B$ in the Eq. 1 (original Hata equation). It is the coefficient in the distance dependence term.

Simi et al. tuned $A_{0}^{1}, A_{1}^{1}$, and their values for open area and suburban area have been presented in Tables 2 and 3 . Their values of $A_{0}^{1}$, i.e., 45.95 and 47.31 , are comparable to $E_{0}$ values of base station Neral under western India and Goilkera, Mahadevsal, and Jaraikela base stations under eastern India. The values of Simi et al. under suburban category in Table 3 also showed similar values for the open area.

In the case of route II (Table 3) measured in suburban area, maximal error is decreased by $2.8 \mathrm{~dB}$, while RMS error is increased by $2.58 \mathrm{~dB}$.

Authors conclude that not only r.m.s. error and standard deviation are important parameters for evaluation of the propagation model tuning process, maximal difference between predicted and measured values has to be also minimized.

\section{Conclusions}

An exhaustive measurements from various narrowband transmitters in open/rural regions of northern, western, southern, and eastern regions of India have been carried out in the VHF and UHF bands for various antenna heights. The observed signal levels of these measurements were utilized to tune the initial offset and slope of OkumuraHata model. In the northern region, the offset values are confined between 40 and 55 and the slope $(\gamma)$ between 0.95 and 1.29. In the western region, they lie in the range of 4559 and $\gamma$ values between 0.8 and 1.43 . Only the base station Pune exhibited a lower value of 32 . This could be due to suburban and medium urban nature of environment prevailing near the base station that dominated the measurements. This leads to an important conclusion that in most of the cases, in this study, medium urban and urban environments exhibit lower values of $E_{0}$, but the reciprocal assertion may not be true in all cases. If one has exhaustive measurement values, one can identify the type of environment through the $E_{0}$ values. In the eastern region spanning the states of Orissa and Jharkhand, $E_{0}$ values vary between 40 and 50 and $\gamma$ values between 0.9 and 1.35 . Only the base stations Goilkera, Mahadevsal, and Posoita exhibited lower values of 15,26 , and 32 . This does not mean that the environment is medium urban or dense urban, but steep terrain changes and elevated terrain lead to high path loss values, and hence, small $E_{0}$ values. The whole study assumes importance in the context that for a country like India with widely varying environments, same values of $E_{0}$ and slope may not hold good, and the values deduced from the present study can be utilized for the design of future mobile communication systems in these regions.

\section{Annexure A}

The detailed specifications of receiver RFT SMV-8 are given below.

1. The frequency is subdivided into five ranges: $30-66$ $\mathrm{MHz}, 66-142 \mathrm{MHz}, 142-300 \mathrm{MHz}, 300-600 \mathrm{MHz}$, 600-1,000 MHz.

Error of the frequency scale after calibration onto the next frequency marker, $\pm 3 \times 10^{-3} f_{\text {input }}+200 \mathrm{kHz}$

2. Error with the measurement of voltage ratios.

Error of the voltage divider within the frequency range 30-300 MHz, $\pm 0.6 \mathrm{~dB} ; 300-1,000 \mathrm{MHz}, \pm 0.9 \mathrm{~dB}$.

3. Input impedance $=50 \Omega, \mathrm{RF}$ instrument connector series $\mathrm{N}$ 4. Selectivity properties

4.1. Bandwidths $120,20,1 \mathrm{KHz}$ (for sweep operation, the additional error of the voltage measurement is $\pm 0.5 \mathrm{~dB}$ )

4.2. IF selectivity

\begin{tabular}{llll}
\hline $120 \mathrm{KHz}$ bandwidth & Drop & $6 \mathrm{~dB}$ & $40 \mathrm{~dB}$ \\
& Bandwidth & $120 \pm 20 \mathrm{KHz}$ & $<300 \mathrm{KHz}$ \\
$20 \mathrm{KHz}$ bandwidth & Drop & $3 \mathrm{~dB}$ & $40 \mathrm{~dB}$ \\
& Bandwidth & $20 \pm 5 \mathrm{KHz}$ & $<200 \mathrm{KHz}$ \\
\hline
\end{tabular}


4.3. Image frequency rejection with in the frequency range $30-300 \mathrm{MHz},>80 \mathrm{~dB} ; 300 \mathrm{MHz}-1,000$ $\mathrm{MHz},>60 \mathrm{~dB}$ Amplitude and frequency demodulation facility available

5. Receiver sensitivity

$12 \mathrm{~dB}$ or better for a level of $-107 \mathrm{dBm}(1 \mu \mathrm{V})$. Signal to noise ratio of $50 \mathrm{~dB}$ or better for RF level of $-87 \mathrm{dBm}$ of $10 \mu \mathrm{V}$ at antenna port

6. Environmental conditions

Operational conditions class according to GDR standard, TGL 9200 B1.1, TII.

Extended ambient temperature range $-30^{\circ} \mathrm{C}$ to $+50^{\circ} \mathrm{C}$. Instrument meets the environmental testing requirement according to USSR standard GOST 9763-67, group of instruments IV.

Transmitter was operating on amplitude modulation radiating output power of $5 \mathrm{~W}$ with a omnidirectional monopole antenna. Receiving antenna is a yagi with gain of $12 \mathrm{dBi}$.

\section{Annexure B}

Table 4 Details of paths and specifications of experimental measurements

\begin{tabular}{|c|c|c|c|c|}
\hline Path & $\begin{array}{l}\text { Tx.ant } \\
\text { Height (m) }\end{array}$ & $\begin{array}{l}\text { Rx.ant. } \\
\text { Height (m) }\end{array}$ & $\begin{array}{l}\text { Freq. } \\
(\mathrm{MHz})\end{array}$ & $\begin{array}{l}\text { Power } \\
\text { (e.r.p) (W) }\end{array}$ \\
\hline \multicolumn{5}{|l|}{ Southern region } \\
\hline $\begin{array}{l}\text { Coastal regions } \\
\text { Andhra Pradesh }\end{array}$ & $16,30,40$ & 3 & 150,440 & 5 \\
\hline \multicolumn{5}{|c|}{ Northern region train measurements } \\
\hline Meerut & 40 & 3 & 320 & 5 \\
\hline Muzzafarnagar & 40 & 3 & 320 & 5 \\
\hline Saharanpur & 40 & 3 & 320 & 5 \\
\hline \multicolumn{5}{|c|}{ Western region train measurements } \\
\hline Vangani & 26 & 3 & 320 & 5 \\
\hline Neral & 25 & 3 & 320 & 9 \\
\hline Pangoli & 46 & 3 & 320 & 5 \\
\hline Talegaon & 115 & 3 & 320 & 9 \\
\hline Pune & 45 & 3 & 320 & 5 \\
\hline \multicolumn{5}{|c|}{ Eastern region train measurements } \\
\hline Chakradharpur & 37 & 3 & 320 & 5 \\
\hline Goilkera & 37 & 3 & 320 & 9 \\
\hline Mahadevsal & 22 & 3 & 320 & 9 \\
\hline $\begin{array}{l}\text { Mahadevsal } \\
\quad \text { (tunnel top) }\end{array}$ & 50 & 3 & 320 & 9 \\
\hline Posoita & 29 & 3 & 320 & 9 \\
\hline Manoharpur & 31 & 3 & 320 & 5 \\
\hline Jaraikela & 18 & 3 & 320 & 9 \\
\hline Bondamunda & 35 & 3 & 320 & 5 \\
\hline Rourkela (P\&T) & 200 (hilltop) & 3 & 320 & 9 \\
\hline
\end{tabular}

Table 5 Mean errors (ME) and standard deviations (SD) of Hata's prediction method (in $\mathrm{dB}$ )

\begin{tabular}{lll}
\hline Base station & Mean error $(\mathrm{dB})$ & $\mathrm{SD}$ \\
\hline Northern India & & \\
Meerut & -1.36 & 3.23 \\
Muzafarnagar & -2.57 & 5.55 \\
Saharanpur & -1.81 & 3.12 \\
Western India & & \\
Vangani & -9.10 & 11.55 \\
Neral & 9.99 & 5.01 \\
Pangoli & -16.17 & 11.83 \\
Talegaon & -3.20 & 9.92 \\
Pune & 0.31 & 5.74 \\
Eastern India & & \\
Chakradharpur & -1.5 & 7.75 \\
Goilkera & -13.1 & 10.70 \\
Mahadevsal (tunnel top) & -18.0 & 7.39 \\
Mahadevsal & -24.7 & 12.56 \\
Posoita & -19.5 & 2.89 \\
Manoharpur & -5.24 & 6.64 \\
Bondamunda & 0.75 & 6.28 \\
Rourkela & -12.44 & 9.04 \\
Jaraikela & -13.1 & 5.68 \\
Southern India & & \\
440 MHz, 40 m & -16.5 & 0.21 \\
440 MHz, 30 m & -16.5 & 0.18 \\
440 MHz, 16 m & -6.0 & 0.70 \\
150 MHz, 40 m & -20.49 & 0.23 \\
150 MHz, 30 m & -20.57 & \\
150 MHz, 16 m & -20.46 & \\
\hline & & \\
\hline
\end{tabular}

\section{References}

1. Prasad MVSN, Singh R (2000) UHF train radio measurements over northern India. IEEE Trans Veh Technol 49(1):239-245

2. Prasad MVSN, Singh R (2003) Terrestrial mobile communication train measurements over western India. IEEE Trans Veh Technol 52(3):671-682

3. Prasad MVSN, Singh R, Sarkar SK, Sarma AD (2006) Some experimental and modelling results of widely varying urban environments on train mobile radio communication. Wireless communication and mobile computing, vol 6. Wiley, UK, pp $105-112$

4. Prasad MVSN, Ahmad I (1997) Comparison of some path loss prediction methods with VHF/UHF measurements. IEEE Trans Broadcast 43(4):459-486

5. Rama Rao T, Rao SVB, Prasad MVSN, Sain M, Ahmad I, Lakshmi DR (2000) Mobile radio propagation path loss studies at VHF/UHF bands in southern India. IEEE Trans Broadcast 46 (2):158-164

6. Medesis A, Kajackas A (2000) On the use of the Universal Okumara-Hata propagation prediction model in rural areas. 
Proceedings of the 51st Vehicular Technology Conference, IEEE, vol. 3, pp 1815-1818

7. Hattori T, Shiokawa T, Abe K (2000) Measurement of microwave, millimeter-wave band propagation characteristics in environments along railway tracks. Proc ISAP 1:321-324

8. Okumura Y, Ohmori E, Kawano T, Fukuda K (1968) Field strength and its variability in VHF and UHF land-mobile service. Rev Electr Commun Lab 16(9-10):825-878
9. Hata M (1980) Empirical formula for propagation loss in land mobile radio services. IEEE Trans Veh Technol 29:317-325

10. Blaunstein N, Andersen JB (2002) Multipath phenomena in cellular networks. Artech House, Artech House Mobile Communication Series

11. Simi IS, Stani I, Zrni B Minimax LS Algorithm for automatic propagation model tuning. http://www.telfor.org.yu/telfor2001/ radiov1/4-12.pdf 